\title{
Cancer Chromosome Aberration Project
}

National Cancer Institute

\section{Source}

National Cancer Institute. Cancer Chromosome Aberration Project. NCI Thesaurus. Code C15939.

$\mathrm{NCl}$ Initiative to integrate the cytogenetic and physical maps of the human genome, generate a repository of BAC clones arrayed across the genetic and physical map, and to develop a publicly available database displaying this clone repository and providing a platform for correlation with other databases of chromosomal aberrations, as well as clinical and histopathological information. 